\title{
COMPARAÇÃO DA RIQUEZA DE GASTRÓPODOS OCUPADOS POR DUAS ESPÉCIES DE ERMITỖES (DECAPODA, ANOMURA) DO DISTRITO DE OLIVENÇA, ILHÉUS, BAHIA, BRASIL
}

\author{
Santos, M.P. ${ }^{1,}$; Monteiro, J.O. ${ }^{1}$ \& Fransozo, V. ${ }^{1}$ \\ ${ }^{1}$ Universidade Estadual do Sudoeste da Bahia (UESB), Campus Vitória da Conquista, Laboratório de Zoologia. \\ *Autor correspondente: teusantos11@hotmail.com
}

\begin{abstract}
Os ermitões utilizam conchas de gastrópodes como abrigo para se protegerem dos possíveis predadores. Este estudo comparou a ocupação dessas conchas pelos ermitões Calcinus tibicen (Herbst, 1791) e Clibanarius antillensis Stimpson, 1859, os quais foram amostrados no distrito de Olivença, Ilhéus, estado da Bahia. As coletas foram realizadas a cada dois meses, de novembro de 2016 a setembro de 2017, durante o período da maré baixa. O procedimento foi aleatório e manual, efetuado por dois coletores durante $30 \mathrm{~min}$. No laboratório, as conchas foram identificadas até o nível de espécie e mensuradas quanto à largura da abertura da concha (LAC) e comprimento total da concha (CTC) e os crustáceos foram removidos, identificados, mensurados quanto ao tamanho do escudo cefalotorácico (CEC) e o sexo registrado. Foram coletados 2783 indivíduos da espécie Clibanarius antillensis (1649 machos, 613 fêmeas não ovígeras, 498 fêmeas ovígeras e 23 intersexo) e 687 indivíduos da espécie Calcinus tibicen (282 machos, 259 fêmeas não ovígeras e 146 fêmeas ovígeras). O ermitão C. antillensis ocupou a maior riqueza de conchas (12 espécies) que $C$. tibicen ( 6 espécies), cuja diferença foi significativa (teste t-Student, $\mathrm{p}<0.05$ ) entre as duas espécies de ermitões. Tanto $C$. tibicen quanto $C$. antillensis ocuparam, em maior porcentagem, a concha Stramonita rustica (Lamarck, 1822), seguida por Tegula viridula (Gmelin, 1791). O padrão de ocupação de conchas pode variar para diferentes espécies vivendo no mesmo ambiente. A diferença na riqueza de conchas ocupadas pode estar associada às diferenças na estrutura populacional de cada população de ermitões, uma vez que $C$. antillensis possui um tamanho médio menor (CEC $=2.68 \pm 0.64 \mathrm{~mm}$ ) que $C$. tibicen (CEC $=3.80 \pm 0.74 \mathrm{~mm}$ ) e as menores médias de LAC e CTC foram reportadas para as espécies de conchas ocupadas exclusivamente por $C$. antillensis. Embora não tenha sido realizada análise de correlação entre medidas dos ermitões e conchas, esta diferença no tamanho médio entre as duas populações de ermitões exige ocupação de conchas proporcionais ao tamanho de cada espécie e, consequentemente, uma ocupação de diferentes espécies de conchas. Além disso, o diversificado padrão de ocupação é resultado da interação de outros fatores, principalmente da disponibilidade de concha presente no ambiente.
\end{abstract}

Palavras-chave: disponibilidade de concha, Calcinus tibicen, Clibanarius antillensis, Paguroidea, Nordeste. 